\title{
Interruptions, Lunch Talks, and Support Circles: An Ethnography of Collective Repair in Steam Locomotive Restoration
}

\section{Christophe Lejeune}

\section{Introduction}

Participative, collaborative, and social Web advocates are celebrating the advent of self-organized online communities of amateurs producing valuable content or artifacts (Lejeune 2011a). However, in many different contexts, enthusiasts have been coordinating collective efforts long before information technologies offered to support it. Indeed, among others, volunteers have been preserving steam locomotives for half a century. Heritage railways depend on a constantly accommodating group of volunteers, who immanently combine their activities. This paper addresses an intrinsically collective phenomenon.

Regarding repair and maintenance, heritage railways offer singular settings. Unlike museums dedicated to industrial legacy, they do more than preserving decommissioned steam engines. In addition, they

\footnotetext{
C. Lejeune $(\square)$

University of Liège, Liège, Belgium

e-mail: christophe.lejeune@uliege.be 
intend to operate steam locomotives and run antique trains. Therefore, they fall under conflicting constraints bound to preserving while using.

This chapter sets out to shed light on heritage railways' "invisible" activities. As I will show, although very efficient, the social organization of these activities is widely informal and, as a consequence, go unnoticed at first glance. Of course, this first invisibility is common to lots of, if not all, social activities. Secondly, the people involved in preserving steam locomotives are not trained professionals, but volunteers. Their non-profit organization is neither a craft corporation, nor a national railway company, nor a large-scale private industry. They do not benefit from the prestige of traditional crafts, public service values, or corporate image. This study is, thus, also an opportunity to underline what they do. Finally, focusing on repair and maintenance, this ethnography covers background activities. Service operators are, by design, concealed to the public (Goffman 1956: 71; Thibault 2013: 23-24, 92, 119). While narratives are subject to retrospective rationalization, ethnography permits to open the black box of these background activities. Shadowing members, I gained access to the actual gestures, discussions, and practices as they unfold behind the walls of a messy workshop.

Dissecting four ethnographic vignettes, I will exhibit different ways to organize, regulate, and adjust repair and maintenance through interruptions, lunch talks and support circles. In the meantime, the creativity demonstrated by members facing unexpected difficulties will question the apparent paradox of the continued use of heritage engines thanks to modern technologies.

\section{A Heritage Railway}

Across Europe, volunteers are working together to preserve and restore railway lines and rolling stock, focusing mainly on steam locomotives, as well as railcars, coaches, and wagons. The Three Valleys Steam Railway is one such non-profit organization, and one of the most important in Belgium. The organization owns a collection of rolling stocks, which has been decommissioned by the national railway companies, such as Société Nationale de Chemin de Fer (SNCF in France or SNCB in 
Belgium). The organization also rents an abandoned rail line from the national railway company. Located in the Belgian countryside, close to the South-West border with France, the line is 14 kilometers long and serves three intermediary stations. At the beginning of the railroad, the first station has a preserved roundhouse where steam locomotives are sheltered. Coaches, wagons, diesel shunters, and railcars can be found on the tracks around the roundhouse. A welcome desk has been built close to the roundhouse. At the other end of the line, a train museum, a cafeteria, and a large workshop surround the final station. A collection of locomotives stand in the yard around the shop.

During the summer, this rolling stock is driven along the railway line. Excursions are organized for tourists. This generates the income needed to fund the association's restoration projects and enables it to maintain a high profile. Throughout the year, on weekdays, the workshop houses a Work Training Center (Centre de Formation par le Travail). This center allows unemployed people to acquire manual know-how with the purpose of applying these new skills to jobs in the industry. On Saturdays, the shop is devoted to the restoration of rolling stock by members of the organization. Although it employs a few paid workers, most of the people working for the organization are volunteers, the majority of whom do not have a professional background in the railway sector. Of course, retired railwaymen also take part in the activities of the association. Some members are still employed by the railway companies, but they are not in the majority. Of the 100 or so members, a variety of profiles can be seen. Although most of the members are men, a few women are active in the organization. Most of them perform gendered activities, such as preparing food, serving drinks, selling tickets, and welcoming visitors. However, a few women also run heavy engines, such as steam locomotives.

As it is often the case in the voluntary sector, a large number of retired people are involved. A wide range of manual professions is represented, including industrial workers, lorry drivers, technicians, gardeners, and tradesmen. The organization's ranks also include retailers and freelance workers (electronics consultants), those from intellectual professions (teachers, service sector managers), craftswomen (blacksmiths), and from the artistic professions (painters, orchestra conductors). 
The activities of the organization are relatively varied, as they include coordinating a large number of people, maintaining and repairing rolling stock (in the workshop), looking after the infrastructure (buildings, bridges, tracks, and points), getting the locomotives and trains moving (preparing, coupling, driving, dispatching), contacting sponsors, organizing and promoting the events, welcoming visitors, selling tickets, and accompanying trains.

\section{Fieldwork}

Operating a decommissioned locomotive on an abandoned railroad requires a team. A driver and a fireman, occasionally assisted by a supplementary crewmember, run the locomotive while one or two conductors accompany passengers in the coaches. However, this front-line crew would not succeed without a large team of volunteers working behind the scenes. This invisible team carries out maintenance and repairs, either in the shop (primarily where the engines are concerned) or on the railway itself (tracks and points require maintenance, too). This chapter's ethnographic vignettes focus on engine repairs (a diesel railcar and a steam locomotive). These do not cover the large range of activities required to operate the train. ${ }^{1}$ However, even restricted to this scope, activities are far from scarce.

I have observed this association's restoration work first hand. I have taken part in its Saturday activities once a month for three years. My frequent attendance makes me a regular, though not its hardest working member (the most committed volunteers are generally present every Saturday). My early contact with the organization, one year before the fieldwork began, suggested that members did not welcome rail enthusiasts exclusively interested in operating steam locomotives. Instead, commitment to repair and maintenance work in the shop was requested. To prove that I was not going to waste their time, I decided to conduct my observation mainly in the shop. This decision surely helps me to be accepted as a peer. It also determined the kind of repairs I witnessed.

I excluded myself from the crews operating the locomotives and performing quick and dirty fixes in-line. Moreover, living far from the 
shop (four hours by train), I rarely attended early Saturday meetings where activities in the shop were planned and organized. Quick and dirty fixes, on the one hand, and planning meetings, on the other hand, were thus excluded from my fieldwork. The present chapter therefore does not address these phenomena. Of course, once I became aware of the consequences of my early decisions, I reorganized my fieldwork: in 2015, I started training to become a member of the crew that runs steam locomotives (and thus perform in-line quick and dirty fixes). At the same time, I took lessons to obtain my driving license that allows me to drive and attend the Saturday morning organizational meetings. These two decisions, though, concern my subsequent (currently ongoing) fieldwork, that this chapter does not cover. Instead, I focus on elements from the first stage of fieldwork, i.e., repair-in-action.

This study is based on empirical material presented through four ethnographic vignettes. The first two vignettes concern a railcar, while the second two relate to a steam locomotive. I was present and participated in these restorations.

\section{Straightening the Brake Linkage}

\section{First vignette}

On 27 April 2014, I was on my way to the heritage railway. As always, I was excited. But that day was special. A few days before, I made a phone call to Oliver, a member of the organization. He told me that, two weeks before, on 13 April 2014, something very unusual, though not too serious, happened to his favourite railcar: it was derailed. No one was injured, fortunately, and hardly any material damage was reported.

Oliver was driving the railcar when the incident occurred. He was surprised and wondered what could have caused this derailment. The incident happened in a place that is not particularly difficult and the train was traveling relatively slowly. Oliver therefore decided to examine the entire railcar, in order to identify the reasons that caused its derailment. He invited me to participate in the diagnostic session, which involved performing a major overhaul of the concerned engine. Such an overhaul differed from the setting I typically observed and participated in the association's shop. 
This vignette concerns a French diesel railcar resembling a long bus on rails. I first came into contact with this railcar when I began my observations, on the first day spent at the workshop, on 8 September 2012. As a novice, I was asked to remove paint marks from the windows of the railcar that I will discuss here.

During the phone call, Oliver gave me an appointment at the initial station (while other volunteers typically gather at the shop adjacent to the final station). The railcar was positioned over a pit of the same type as those found in the workshop, apart from one detail - this pit is outside and therefore not located in the actual workshop. The two association members that I accompanied, Oliver and Ian, started by looking at the brake linkage. The linkage is a worm screw that holds the brake shoes and wheels in place.

The end of this threaded rod was slightly bent, probably because it came into contact with the rail when the railcar was derailed. The first repair would therefore involve the straightening of this metal rod. The method used was very instructive. One of the two members picked up an old tube that was lying around inside the locomotive shed. It was actually a steam locomotive tube, through which hot gases from the firebox would pass, before reaching the smoke box (the functioning of a steam locomotive will be described in detail below). This tube was used as a tool, in an attempt to straighten the brake linkage. Sliding the end of the brake linkage into one end of the tube meant that the volunteer had enough leverage to straighten the linkage with his bare hands.

However, this first attempt failed. In fact, as the linkage was relatively close to the bottom of the railcar body, the tube touched the bottom of the body and there was not enough space to straighten the threaded rod.

The volunteers stared at each other. "We need a car jack," they said in unison. Ian asked me to get a few pieces of wood from a junk pile next to the roundhouse. Meanwhile, he went to look for a jack in his own car, which would normally be used to change a tire. As Fig. 8.1 shows, he positioned the jack on the rail thanks to a few pieces of wood and placed a small one between the top of the jack and the end of the threaded rod. Doing so, he grumbled, "I told them a dozen times that the shed should be provided with an industrial pneumatic jack." He then turned the crank on the jack, in order to lift its end, which gradually straightened the threaded rod. While Ian was about to release the pressure on the crank, the two members then noticed the threaded rod was returning to its 


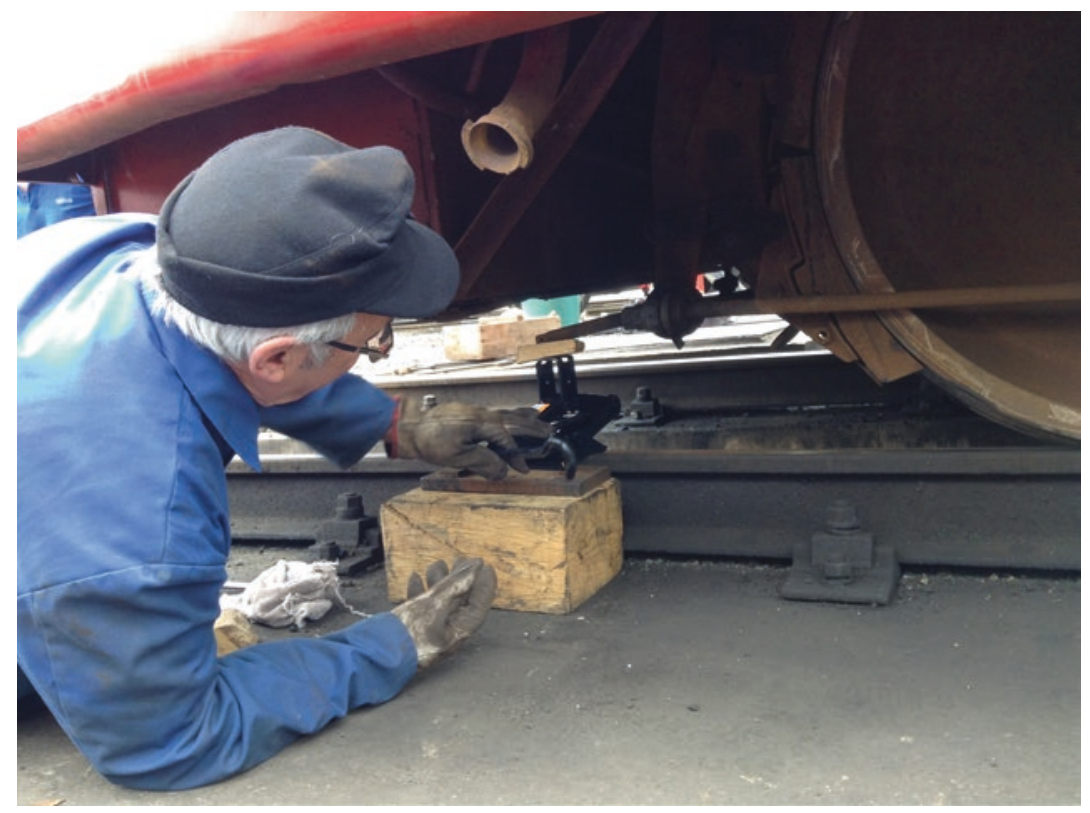

Fig. 8.1 Operating the car jack (๑ Photo: C. Lejeune)

initial bent position. They instantly diagnosed a "spring effect." Without a word, Ian made an additional turn of jack handle to counter this tendency. The threaded rod had now returned to its rectilinear position in alignment with the entire linkage.

\section{Improvizing Tools}

This vignette illustrates a typical type of repair. There had been an accident and breakdown (the railcar was derailed), which led to parts being altered and adversely affected (the brake linkage was bent). Because steel is quite flexible, the rod did not break during the derailment. The same reason rendered its straightening possible. In this case, nothing was irreparably broken; instead, the bending was reversible with nothing more than a simple tool and some manpower. With the aid of a car jack, the railwaymen straightened the bent rod to its original position. 
The work completed by the volunteers involved restoring the threaded rod, which meant returning it to how it was before the problem arose. This vignette resembles the work completed by technicians in a car garage (Dant 2005: 109). In both cases, the task consists of returning an object to a previous state. Such restorations match the most straightforward definition of repair.

This restoration required no additional material other than manpower and tools. Nevertheless, unlike a car garage or the shop (located at the opposite end of the line), the roundhouse is not provided with dedicated tools. The volunteers must improvise-a car jack replaces an industrial jack, and a boiler tube and some pieces of wood are recycled from scrap material. This interesting phenomenon surrounding the repair and maintenance work is similar to what is documented by the editor in chief of Make magazine and advocate of the Do-It-Yourself (DIY) philosophy. While building a chicken coop, Mark Frauenfelder (2011: 99) scavenges his junk pile for needed materials. He discovers the immense resources that can be extracted from scrap material. Indeed, tinkering rests on odds and ends, as stated by Claude LéviStrauss (1962: 36). Keeping, gathering, and collecting miscellaneous items allows for the self-reliant creation of a substitute when tools or spare parts are lacking.

In a different context, the required manpower could have been provided by a single person. For instance, Mark Frauenfelder insists that he built his chicken coop on his own. Similarly, some car technicians perform similar repair and maintenance alone (Dant 2005: 111 \& sq.). The setting is, however, clearly different, as a locomotive covers a larger space, thus allowing more than one person to gather in the pit, for instance. But material dimensions, such as size, are not sufficient to explain why locomotive restorations are collectively achieved. Unlike technicians, most volunteers are not trained in mechanics. Working in teams allows for the knowledge, skills, and know-how to be shared, spread, and transmitted among volunteers. The bent rod is restored by a team of two close members, assisted by an apprentice-me. For two old friends who have known each other for 38 years, little conversation is required to decide what to do: substituting a car jack for a pneumatic jack, straightening more than was apparently needed to counter 
the spring effect, or using a boiler tube as a lever. Sharing comparable experiences, they cooperate smoothly. Resting on ingrained habits, their longstanding complicity allows for a fine-tuned mutual adjustment and prevents further issues.

Finally, the two co-workers performing this restoration appear autonomous, being efficient while resting merely on their shared experiences. Through a similar issue, the next vignette shows that they are less isolated than they first appear.

\section{Tightening the Bogie Cables}

\section{Second vignette}

"Wait a minute," said Oliver while leaving Ian and myself for a moment. Back from his car, he showed us a complete original technical documentation for the railcar. During the two weeks following the derailment, Oliver sought out the origin of the problem. Other associations that owned a former railcar of this type, together with his contacts at the French national railway company (SNCF), enabled him to identify a variety of factors. As a result, he obtained advice from people with experience on this type of engine, as well as the technical document, which we were admiring for its excellent condition.

Based on these experiences and documents, Oliver offered to examine how the bogies were secured. To fully understand this suggestion, I first had to remember that a bogie is a small trolley with 2 or 3 axles. They are used on a large number of coaches, wagons, railcars, and locomotives, because these rolling stocks are so long that they would struggle to take bends if the axles were directly attached to their chassis. Generally, bogies are fastened to the chassis using a pivot. On this particular railcar, they were secured in a different way. A metal cable is used to connect them to the chassis.

Oliver pulled on the cables in order to assess their condition. He immediately determined that these cables were not sufficiently taut. Tightening these cables would therefore be the second task undertaken by the two volunteers. A screw was provided for this purpose. As it had rarely been operated, and had been exposed to all types of weather, this screw proved particularly difficult to move. It was therefore necessary to clean the place where it was located. I removed the dirt. Then, Oliver used a 
wrench, pulled with all his strength and leaned on the wrench with all his weight, although unsuccessfully. Ian joined him to combine their efforts. However, even the two of them together failed to achieve any result.

Without stopping for a moment, Ian asked me to fetch a tube of the same type as that used to try and straighten the brake linkage in the locomotive shed. Once I had found the right tube, he joined me again. Using a vice, we squeezed the end of the tube. By changing the round section into an oval section, we widened the end of the tube. Back in the pit, under the railcar, this modified tube enabled us to extend the wrench handle. Once pushed into the modified tube, the wrench had a lever arm of almost two meters. However, with its extended handle, the wrench proved uneasy to manipulate. Each attempt to turn the screw resulted in hitting one of the pit sides. Ian and Oliver moved to a different tool arrangement. They finally managed to handle the extended wrench from the pit by sliding the long arm between the track and the chassis of the railcar (see Fig. 8.2). This time, the strength of the two volunteers was enough to turn the screw and tighten the bogie cables.

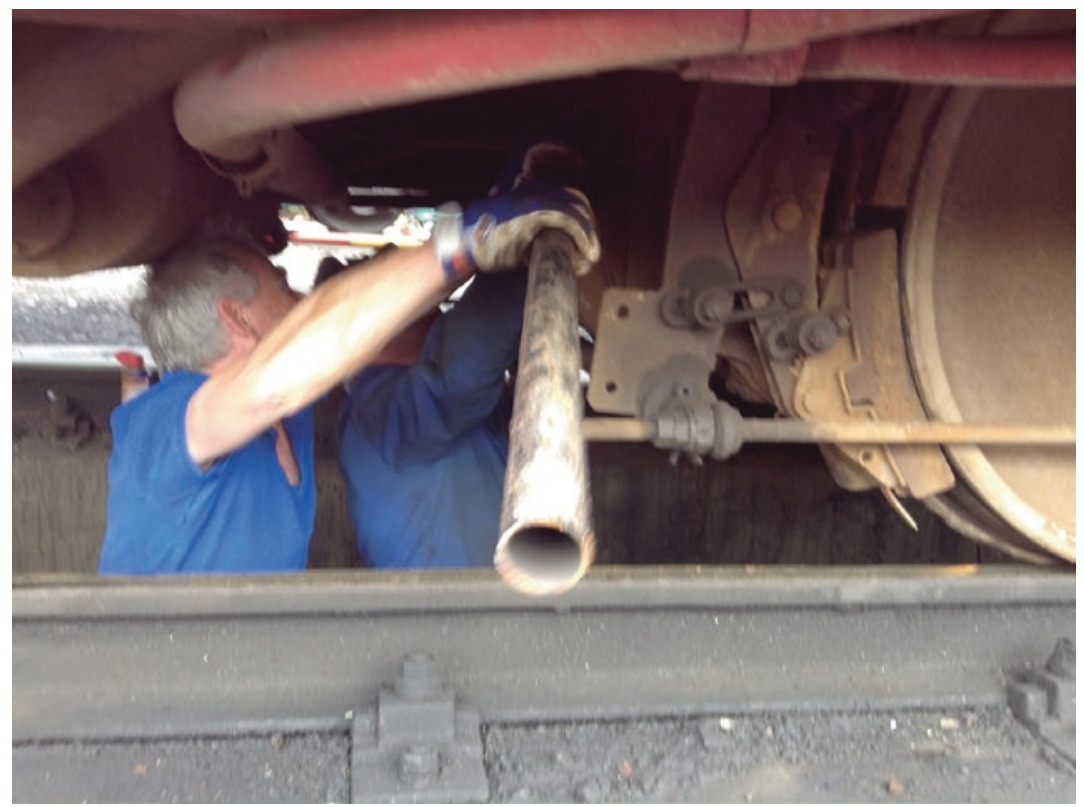

Fig. 8.2 Arranging the extended wrench (๑ Photo: C. Lejeune) 
Approaching the pit, Ivo, the dispatcher, asked us if everything was going well. He weighed up the situation before giving us a piece of advice. He suggested that we should not overtighten the cables, so that the railcar could still handle the tightest bends on the network without any difficulty after the adjustment. Finally, Oliver, Ian, and Ivo managed to agree on the ideal tightening strength.

\section{Follow-Up Maintenance}

Similar conclusions can be raised from the bogie cables issue as from the brake linkage restoration. As in the first vignette, these non-professional "workers" proved able to invent, modify, and repair their own tools, using the same materials that were used to build the steam locomotives. The tube taken from a steam locomotive boiler was actually used as a lever arm to straighten the brake linkage and to turn the wrench, in order to tighten the bogie cables.

At first glance, the repair itself looks similar. The loose cable can be tightened with nothing more than an (extended) wrench and (significant) workforce. This restoration nevertheless presents slight differences. Unlike the bent rod, the slackening did not result from the derailment, but rather is the alleged cause of the derailment. The slackening itself was not caused by a specific incident but occurred gradually over time. Strictly speaking, tightening the cables is a part of the overhaul activities. While the former operation is more like typical repairs, the latter normally falls under maintenance activities.

In fact, the task of tightening the bogie cables was certainly undertaken regularly by the maintenance staff when this railcar was in regular service for the national company. While the locomotive was used for many years by an association of volunteers, these same cables were not tightened during regular maintenance work. The derailment was an alarm signal that drew the volunteers' attention to the fact that something was missing from the regular maintenance of the rolling stock. That's why a major overhaul was organized after the problem arose. In fact, the cables in question were not tightened enough and the volunteers' task was to conduct a kind of follow-up maintenance. 
Rather than preventive, the overhaul here is retroactive and reparative. It is fairly similar to a repair, as the problem has already arisen. This suggests that actors make no great divide between repair and maintenance. Indeed, everyday activities of the shop seamlessly combine repair and maintenance operations. Both straightening the bent rod and tightening the loose cables can thus be considered as restoring the locomotive to a previous state.

As noted in the previous section, restoration implies fixing a problem caused by a breakdown. In many cases, the damage consists of something not only disfigured but also broken into many pieces. Restoration then requires reassembling what has been broken. Pieces are joined together with glue, solder, or filler metal, or can be tied together with a hose clamp or fastener. A substance, such as glue or solder, or a tie, like a hose clamp or nail, is supplied to hold pieces together, but no original component is replaced.

Straightening, gluing, and fastening are common activities involved in the restoration of a damaged device to its original state. Such fixes do not require in-depth investigations to identify the cause of the problem. Unless something is irreparably broken, actions can be taken as soon as the affected component is identified.

\section{Breaks and Interruptions}

As with the brake linkage, the intervention on the bogie cables rested upon Ian and Oliver's combined workforce. Of course, an extended lever arm was needed. But this strategy is not exclusive to locomotive maintenance. Car technicians also happen to use improvised tools such as a length of pipe to extend spanners (Dant 2005: 112, 128) or a tire lever to adjust a sliding van door (Dant 2010: \$3.3). As noted for the previous vignettes, such a tool arrangement allows car technicians to conduct this kind of repair alone. However, while Ian was able to straighten the bent rod alone, here, Oliver's workforce was not sufficient to turn the extended wrench. A second member's workforce was required. Contrary to the first restoration, this repair justifies teamwork for material purposes. Indeed, locomotives have significantly heavier engines than cars and, in selected occasions, such as here, size and 
weight matter. But differences between the two vignettes go beyond material features.

In the first vignette, the restoration rested on the smooth coordination of the two volunteers. However, the second vignette's restoration benefited from additional resources. First, Oliver's social network provided him with access to useful technical documents about the tautness the cable should be adjusted to. ${ }^{2}$ In parallel, Oliver asked another association to confirm the relevance of such a setting for use in tourism.

In addition, a third person joined the original scene, bringing unexpected advice that influenced the final adjustment. Such an intrusion is not unusual. Indeed, volunteers frequently interrupt what they are doing. In such occasions, they usually move to their closest co-worker. They stand around, attending to others' repairs. The observed person can ascribe a specific meaning to the attendance according to his or her status, seniority, authority, or self-reliance. A novice may dread a controlling gaze over his shoulder or expect help to be provided. In contrast, an experienced or confident worker expects his dexterity to be admired. Occasionally, when a repair proves to be difficult, some members might also demonstrate irritation over others watching them work.

Sometimes, the onlooker may commiserate or comment on what is done, just as Ivo did. By doing so, present volunteers indicate that they care about what others do, reinforce themselves as team members, and make themselves available for further help or advice. As for mere presence, comments may be seen as either constructive or critical. To avoid resistance, suggestions are formulated within a subjunctive mode, which stimulates cooperation (Sennett 2012: 23). How such sights and comments are interpreted depends not only on self-reliance and seniority, but also past relations. Although with equivalent standing in the hierarchy, Oliver and Ian took Ivo's piece of advice very differently.

\section{Support Circles}

A spectator like Ivo does not stay alone for long. Other volunteers join him. Together, they form a circle of onlookers around the activity. These circles resemble the way jazz players arrange themselves when one of them performs a solo improvisation. Their watchful listening manifests 
support and availability. Similar support circles form around Repair Cafés tables (Rosner 2014) or, in the industry, around workers demonstrating their mastery of brazing (Dodier 1993). Thanks to such gatherings, two to five members share knowledge; the spectators see what the others are doing and stay up-to-date by doing so. If a novice is present, the circle is an occasion to explain what kind of repair is being conducted, and how and why it is achieved.

Often, the attendance or the comments of viewers stimulates the observed person to interrupt what he or she is doing. An informal meeting then occurs, providing an opportunity to exchange tips, as when Ivo advises not to overtighten the bogie cable. These interruptions allow the volunteers to collectively adjust how repairs are conducted. When a discussion emerges, each of the participants explains what he or she is doing, how he or she plans to achieve it, and the difficulties he or she anticipates. Every participant shares advice on the others' activities.

Within a few hours of work, each volunteer has the opportunity to explain what he or she is doing half a dozen times and to collect at least as many alternate solutions. Some of these proposals are included in the next story, as alternative options to solve the problem. When one of the options is approved by many spectators, the volunteer tends to integrate it to his strategy and adapts his story accordingly (see Orr 1996 on "war stories" and their contribution to repair work).

In contexts ruled by scientific organization of labor, such as assembly lines or production factories described by Linhart (1981) and Roy (1952), these interruptions would be problematic. Instead, in a shop not governed by imposed pace or quota, a volunteer does not infringe on official rules when he interrupts what he or another member is doing.

Better, in a voluntary context, repeated breaks fulfill a productive role in the social organization of repair. Such a double interruption ritual provides mutual awareness. These social engagements allow for the adjustment of repair activities. What an outsider would consider as endless chatting or as unproductive loss of time represents, from the team perspective, an efficient way to coordinate collective activities.

The productive role of support circles should however not be overestimated. Not all breaks result in a support circle, nor do all support 
circles succeed in finely adjusting a collective repair. Some interruptions might represent a simple opportunity to rest, to spot trains, or to chat about the weather. Someone not involved in the task from the start might fail in taking stock of the situation. His or her suggestions are then likely to have already been mentioned. They may also be completely off topic, and thus prove to be useless. Contributions of this kind might exasperate the recipient. A volunteer may also react badly to a piece of advice, even given with the best of intentions. Although rare, some critical comments may also occur. As with any group, the collective of locomotive keepers is not paradise on Earth.

In brief, breaks and circles stimulate cooperation when they provide mutual awareness, availability, help, constructive comments, or learning. In contrast, irrelevance, critiques, contempt, pride, misunderstanding, admiration, and mere demonstration of dexterity hinder the ability to work together (Sennett 2012).

This second vignette exhibits additional layers of the collective shaping of repair. As with the restoration of the brake linkage, the bogie cables were not adjusted by an isolated individual. Instead, the restoration rested on the kinship of two close friends. People devoted to adjusting the bogie cable were endlessly consulting each other. Moreover, other members do not miss opportunities to intervene while the repair unfolds, such as Ivo did. On these occasions, support circles may orient the ongoing activity. The repair also benefited from assistance outside the organization. When required, the association can count on external networks, like employees from national railway companies or locomotive keepers from other associations. Therefore, neither the volunteers nor the association proved to be isolated (on extended networks of repair work, see Houston in this volume).

\section{Replacing the Blower}

\section{Third vignette}

On a track close to the pit where Ian and Oliver were restoring the railcar, another member, Larry, was firing up a former coal mine locomotive. I temporarily left the pit and went to ask Larry how things were going. 
When I approached the cab, I saw Larry facing a tall flame escaping from the firebox. He swore. "This is not supposed to happen," he explained. "Draught is insufficient."

In order to understand Larry's diagnosis, I had to remember my first contacts with the field, two years earlier, when I was explained how a steam engine functions (I will relate this episode in full detail in the next section). As an apprentice, I learned that a steam locomotive is built around a firebox, a tube boiler, and a smoke box.

To fire up a locomotive, the fireman starts by lighting the fire in the firebox, first using soaked cloths and then pieces of wood. Coal is provided afterwards. While burning, coal produces smoke and hot gases. These hot fumes travel along the tubes, which pass through a boiler filled with water. They gradually heat the water, which is then converted into steam and provides the power used to propel the locomotive. After the fumes produced by the firebox have heated the tubes, they come out in the compartment at the front of the locomotive, which is known as the smoke box. In the same way, after the pressurized steam has propelled the locomotive, it also ends up in the smoke box.

Smoke and steam are discharged from the locomotive through the chimney above the smoke box. As with open fires, the locomotive needs a draught if it is to function properly. The more easily the combustion gases and steam can escape from the smoke box, the better the draught. This evacuation ensures that the firebox produces sufficient heat, so that there is enough pressure inside the boiler to propel the locomotive.

The smoke box is fitted with a blower. The latter consists of a pipe pierced with very small holes, through which the pressurized steam escapes. It causes the gases contained in the smoke box to be blown towards the top of the smoke box and directed towards the chimney. This device therefore makes it possible to regulate the draught.

Throughout the day, Larry and his crew experienced problems related to draught. I personally witnessed these difficulties as they attempted to get the locomotive moving after it had suffered problems on a few journeys. A diesel shunter came to the rescue of this steam locomotive, which was not powerful enough to pull the train.

From mid-day and through lunch, the reasons for this failure were discussed with some of the volunteers, including Larry and Darin, who was to run the steam locomotive the next day. Teams that run steam locomotives take frequent breaks throughout their working day. As railwaymen 
are exposed to strong heat from the firebox, these breaks enable them to stay fully hydrated. But breaks devoted to drinking a bottle of water are also an opportunity to coordinate the crewmembers, who organize train journeys on the railway line, and the team that works in the workshop, located at the end of the line.

In this case, the diagnosis focused, from a very early stage, on the blower. This pipe pierced with small holes, through which steam escapes, is meant to direct the exhaust gases towards the chimney opening, at the top of the smoke box. Larry and Darin's diagnosis pointed to the material from which this blower is made. According to them, the metal used was not sufficiently heat-resistant, causing the blower to bend slightly as the temperature rose. If the blower bends, the steam no longer travels in the same direction and is transferred less towards the chimney. This may explain the reduced draught inside the smoke box, tubes, and firebox.

On that day, the locomotive struggled to fulfil its purpose. The next morning, I joined Darin who was cleaning the smoke box before the locomotive was fired up. The two of us were standing in front of the locomotive, which had its smoke box door open, and looked at the infamous blower, as well as the ends of the tubes that come in the smoke box.

Darin picked up a rasp and rubbed it on the blower, where he discovered an orange metal (Fig. 8.3). "That's it," he said. "It's copper." In his view, the conclusion was clear. The blower, made from copper, was unable to withstand high temperatures and directed the gases contained in the smoke box in a direction which was not precise enough to provide an adequate draught. I then asked Darin about the possible options. He considered the idea of using Inox cables to hold the blower in place. Over the next few weeks, the workshop made a new blower from steel (which is more heat-resistant) and replaced the original copper blower with this new device.

\section{Replacement}

Restoring or reassembling is not always possible. This repair differs from the two previous ones in that no incident or breakdown caused the problem. A diagnosis step was therefore needed. The blower did not suffer from deficient maintenance. It did not need to be restored. It had to be replaced. The need to replace may depend on the material. Pieces made 


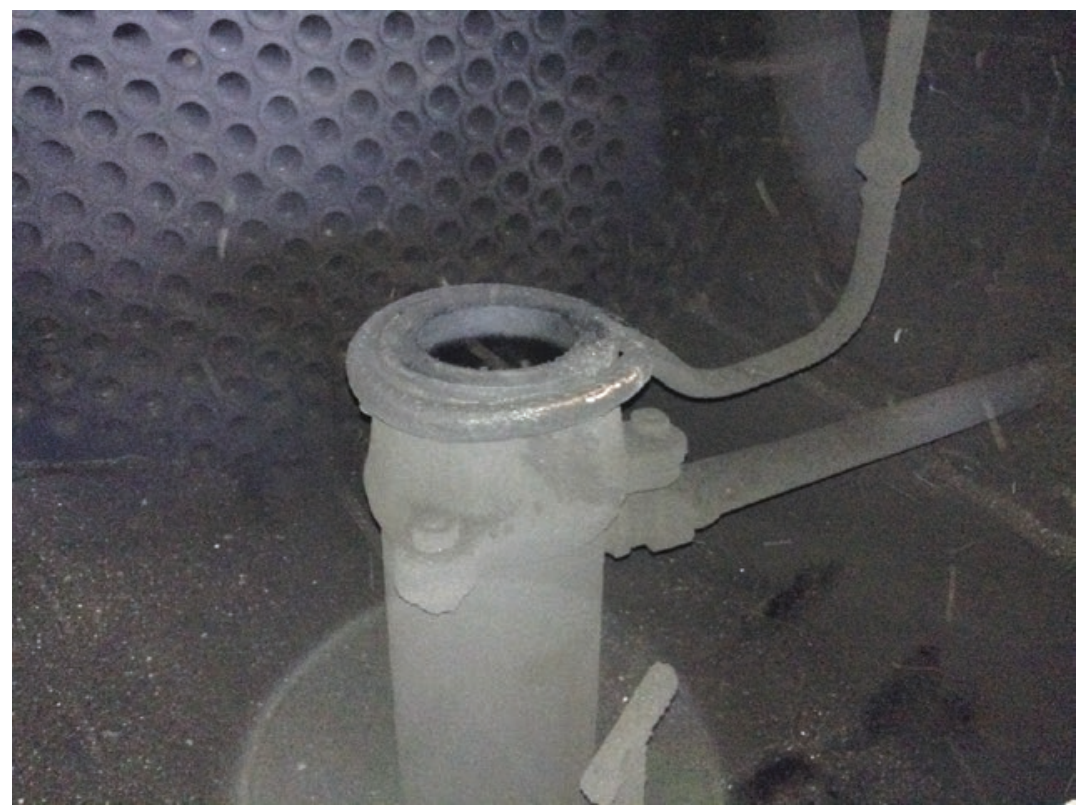

Fig. 8.3 Inspecting the blower (๑ Photo: C. Lejeune)

of rubber cannot be glued or soldered. Similarly, corrosion over time prevents restoration. Deformed bearings, corroded boiler tubes, fatigued fireboxes won't be restored or reassembled but rather have to be replaced.

In everyday life, when a fuse blows or a belt cedes, we buy spare parts. Hardware stores provide spare parts to replace used components. Replacement occupies a relevant space alongside restoration and reassembly. It does not necessarily require different skills than restoring or reassembling. However, tools and manpower do not suffice any more. Spare parts are needed. The availability of these spare parts depends on existing distribution networks.

Maintaining locomotives unavoidably involves replacing worn components. But a steam blower is more difficult to obtain than a light bulb. Given that spare parts are not available for decommissioned locomotives, railway enthusiasts build substitute components from scratch.

In his famous book Zen and Art of Motorcycle Maintenance, Robert Pirsig (1999: 457-458) reports how a welder reconstructs a used chain guard. With no spare part available, the welder uses steel filler rod as 
a material to construct the missing piece. Because his chain guard is made of a thin sheet of metal, Pirsig was skeptical about such a strategy and feared the welder would punch holes in it. For him, brazing would have been a more appropriate technique. He was thus anxious when he entrusted his chain guard to the old welder. However, he admired the welder's technique and complimented him on the "beautiful" result.

The welder's repair occupies an intermediate position between reassembling and replacement. The filler metal is normally used as glue to reassemble pieces. Here, the welder uses it as building material. He constructs the missing component with what is on hand at the moment.

Here, the replacement of the blower did not result from a breakdown, but consisted in a modification of material. Such a substitution contradicted my assumptions. When I started my fieldwork, I assumed that preserving the heritage of steam locomotives implies that the original materials and designs should remain intact. However, volunteers demonstrated no hesitation when an original blower had to be replaced with a new device, made of a material and with tools or techniques from our contemporary society. Substituting materials or applying modern techniques to legacy rolling stock is definitely not an issue for them. "We reconstitute antique engines, but not with antique techniques," Larry confided on 6 September 2014.

\section{Innovating in Preserving}

Unlike archaeologists, locomotive keepers do not attempt to recover historical labor methods. They are rather concerned with running vintage trains. Because replacing worn components is unavoidable and granted that substitute devices will never behave exactly like the original ones, reconditioning old machines requires flexibility. Facing multiple constraints, those concerned with railway heritage prioritize their criteria. Running functional steam locomotives prevails over strict preservation. The Inox cables and the new blower fall under such a compromise.

Comparing the blower to water tanks expands the understanding of their purposes. Nowadays, steam locomotive water tanks are not fastened with solid rivets, but welded. Modifying the appearance of the side tanks 
is nevertheless out of the question. Consequently, the shop team places ornamental rivets along the tanks to preserve the appearance of the steam locomotive. In this instance, the preservation of railway heritage combines the acceptance of new materials, techniques, and tools, while retaining the appearance of the old train. The renewal process of these steam engines entails making new things look old (Roux 2008: 73).

It is therefore likely that the blower modification is not an issue because it allows the locomotive to be functional without affecting the esthetics of the engine.

The replacement of the blower nevertheless did not completely solve the draught issue, which kept on preoccupying Ray, the association's head director. He was constantly thinking about it, even while busy in his position at an industry factory. He thought of a breakthrough on a weekday and immediately phoned the Work Training Center housed in the workshop. The instructor, Leo, is a member of the association. Ray asked Leo to check the smoke box ceiling of other locomotives, stationed in the museum and around the workshop. Leo reported that, contrary to the coal mine locomotive, most of them were fitted with a cone aimed at collecting exhaust gases and directing it towards the chimney. On the next Saturday, Ray proposed to forge such a device, called a petticoat pipe, and to insert it in the smoke box of the steam locomotive experiencing draught issues.

This episode exhibits that the collection of locomotives deteriorating around the shop fulfills a threefold purpose. First, some of the decommissioned locomotives will be reconditioned, although only a few of them will become operational. Second, other locomotives are preserved for their components; when an engine is dismantled, many pieces are likely to be reused (Harper 1987). Even perforated, a boiler tube can help, for instance, to straighten a bent rod or work as a wrench extension arm. But locomotives are not only collected for their components. They also constitute a collection of the wide variety of steam locomotive equipment. As such, they supply information on the original designs and can be used as a diagnostic tool when a problem occurs on a preserved machine. For instance, when the team tries to solve the draught problem of the small steam engine, inspecting smoke boxes of various engines reveals that a petticoat pipe was missing. 


\section{Heritage and Amnesia}

When I returned a few weeks later and was told about this story, I asked Ian why the locomotive did not originally have this petticoat pipe. "It is quite possible that it used to have it," he answered. He suggested that it might have been removed when the locomotive was disassembled and reassembled in the shop, perhaps during its last overall (two years before) or during another modification in the shop. The cone was possibly not put back again, due to it being considered unnecessary. Or it might have been so corroded that it was removed from the smoke box and thrown away with the firm intent to build a new one. Perhaps this plan was forgotten between two Saturdays. Or, less likely, the volunteer that took this decision might have left the organization in the meantime.

It is therefore uncertain whether the petticoat's addition is a restoration or an innovation in itself. However, this uncertainty did not preoccupy the volunteers. They did not need to know whether the locomotive had this petticoat pipe when it was originally designed almost seventy years ago. It was enough for them to diagnose the problem and look at how it has been resolved in other locomotives, in order to adapt the device to the relevant engine. This work on a locomotive engine did not require them to know its precise history. The members care about efficiency rather than about the original design of the blower and the petticoat pipe. Perhaps such a doubt is easier to accept because, contrary to the water tank rivets, both devices are hidden in the smoke box, and thus will not affect the esthetics of the locomotive.

Tim Dant (2005) depicts a case similar to the replacement of the petticoat pipe. He describes how two technicians remove and replace a whole car engine. They arrange the removed parts in boxes of different sizes, on the ledges of the engine compartment and even "on the floor mixed with sockets and other tools" (ibid.: 119). Their concern in refitting the engine is so tense that they "inhabit" these bits. They "read" the way parts fit together and manage to reassemble the whole engine by trial and error, without any instruction manual. 
Although similar, the petticoat issue made the reading a bit more complex. Because shop activities are shared among a lot of people and because a large amount of time had elapsed between the disassembly and the re-assembly, the flow of action was interrupted so that the location of the original petticoat pipe and even its existence became unknown. Ignoring whether the smoke box was originally provided with a petticoat pipe is the drawback of a volunteer team.

Finally, the draught issue made clear that preserving and running heritage locomotives requires prioritizing paradoxical purposes. While preservation suggests engines to remain as they were, operating rolling stock unavoidably causes wear and tear. Maintaining a heritage railway requires the combination of paradoxical features, such as being conservative and creative. This can be complex and puzzling, which may include trial and error, as the next vignette shows.

\section{Cooling Hot Boxes}

\section{$\underline{\text { Fourth vignette }}$}

The steam locomotive that encountered the blower issue reminds me of the first day I spent in the workshop, on 8 September 2012. When I arrived, I was assigned the task of cleaning the body of the same steam locomotive. Definitely, cleaning is a typical assignment for a newcomer (Crawford 2009: 75). Another volunteer, Luke, was firing up the locomotive while I was starting to clean the sides of the body. I was soon interrupted by other members who noticed that I was new and welcomed me to the shop. As they introduced themselves, some members gave pieces of advice. One of them provided me with a larger bucket and with a cloth in addition to the sponge I was using. Another counselled me to start with the top of the body, rather than the sides, given that the temperature of the boiler was gradually rising.

From time to time, some visitors surrounded the locomotive. "Is it heating?" they shouted at me. A few of them started questioning me, giving advice, and concretely exhibiting the community of railfans. Wanting to make a good impression to my new colleagues, I remained devoted to what I was doing and did not jump off the locomotive to answer. This reaction showed that I was not yet used to support circles. 
Given the heating process takes 3 to 4 hours to complete, Luke had many occasions to facilitate my initiation. We indeed took several breaks together. These breaks represented opportunities to start my apprenticeship. Luke was the first to explain how a steam engine functions (see the previous section). Concurrently with these factual explanations, the ongoing breaks were teaching me the underlying ritual of the double interruptions.

When the steam attained a sufficient pressure, Leo joined us in order to test the locomotive. These tests involved several manoeuvres in the railway yard (tracks and points) around the workshop. As each time a locomotive starts moving, the driver gives a whistle signal. Given it did not match a regular schedule of the line, such a sound sufficed as a call for people working in the shop. Some of them interrupted their activities to come and admire the steam locomotive in motion. Unfortunately, very quickly, Leo climbed down from the locomotive, pushed his arm under the bodywork and, with a tense expression, exclaimed "Hot box," meaning that the axle box was overheating. ${ }^{3}$

\section{Discovering Lunch Talks}

It was midday. The three of us interrupted our tests and joined the other volunteers for lunch. As the weather was mild, we brought out a few chairs, so that we could eat outside in the fresh air. While we ate, my two workmates talked about the results of the tests. The score of people present discussed possible solutions.

Lunch is of dramatic importance for the collective coordination of the team. At noon, all shop activities come to a halt while the team members gather to share a meal. In contrast with support circles, gathering only subsets of the team, lunch is an interruption shared by all the people present in the shop. Stories previously developed in the shop are expanded during this time. With everyone present, this is the common place to review current issues, list plausible causes of locomotive failure, contemplate possible solutions, and keep each other up to date. In doing so, the team collectively diagnoses problems. Lunch talks provide an opportunity to exchange tips and coordinate repairs.

That day, the lunchtime discussion was dedicated to a collective brainstorm on the hot box issue (Orr 1996). I then realized that everyone was aware of the problem, which frequently affects this small 
locomotive. In order to reduce overheating, the volunteers had already tested increasingly thicker types of oil. Working in the industry, Ray identified the thickest oil. Leo explained to me that this oil is so thick that it feels like velvet if you let it run between your fingers.

As using this thick lubricant did not appear to produce the desired effect, the team decided that more serious steps needed to be taken with the locomotive. A couple of weeks before I started my fieldwork, the locomotive was therefore returned to the workshop. It was positioned over a pit and lifted (i.e., its wheels were no longer touching the rails) so that it was possible to work directly on the axle boxes. While explaining, Leo showed me some pictures on his smartphone. Another member, Serge, shot these pictures in the shop and published it on his blog (see Figs. 8.4 and 8.5).

Ray commented on Fig. 8.5. Inside the boxes, the axle comes into contact with the rest of the chassis through a bearing. This bearing is a concave piece of bronze, whose bore is coated with an antimony

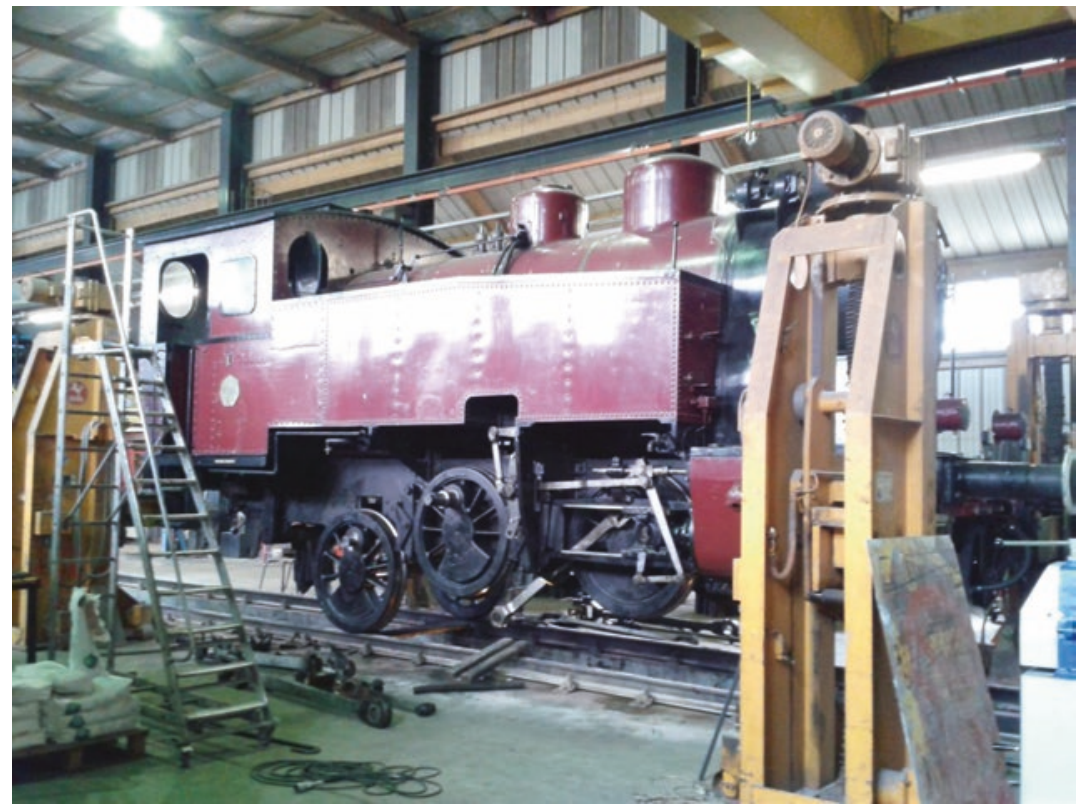

Fig. 8.4 Lifting the locomotive (๑ Photo: Serge Poncé) 


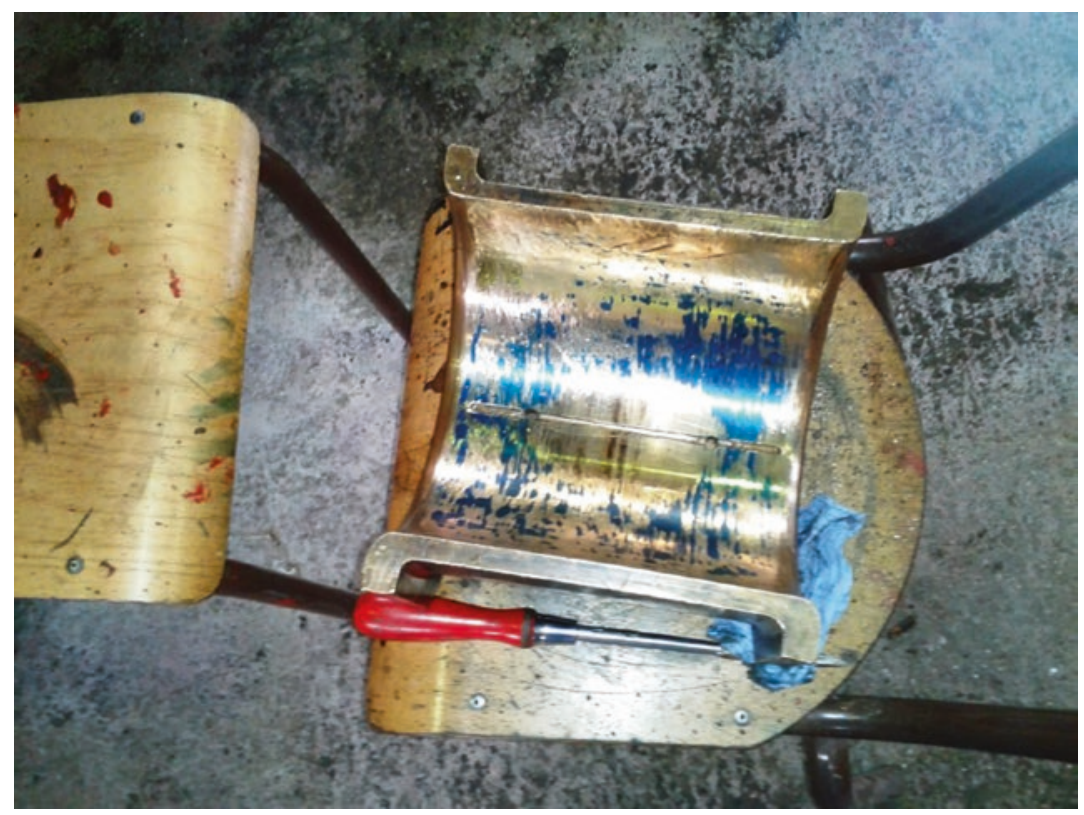

Fig. 8.5 Engineer's blue (๑ Photo: Serge Poncé)

alloy. In order to detect places affected by excessive friction between the axle and the bearing, the rear axle was smeared with some Engineer's blue paste. As expected, there were many blue marks. The first solution envisaged smoothing the concave part, which comes into contact with the axle. This antimony part was therefore machined, in an attempt to reduce the friction that was causing the axle box to overheat. Readers interested in (smaller) bearings are invited to read Tom Dant's chapter in this volume.

Combined with the thick oil, smoothing the bearing was seen as a solution to the hot box problem. The tests conducted with me belonged to a series of tests over several weeks. That day's session was the first since the locomotive was brought back down onto the rails. Unfortunately, these tests proved inconclusive. The axle box was still overheating. 


\section{Insulating the Ash Pan}

During discussion between the volunteers, another solution was proposed. Leo offered to insulate the ash pan under the firebox. His suggestion was based on the following reasoning: a locomotive's firebox is similar to an open fire. Red-hot coals are placed on a grate. The cinders created when they combust fall through the grate into an ash pan so that they can be easily removed. Due to the temperature inside the firebox, these cinders are very hot. They conduct heat to the sides of the ash pan. Because the locomotive is made of metal, this heat is likely to spread, via the chassis, to the axle boxes, which overheat as a result. Insulating the ash pan could therefore present a solution to the hot box problem.

A substantial amount of work would be required to complete Leo's solution before the end of the season. Members around the table were therefore divided about dedicating their efforts to an option whose outcome remained uncertain. However, Leo had another trick up his sleeve. As the instructor supervising the Work Training Center in the shop during the week, Leo offered to ask the trainees to insulate the ash pan. Indeed, on select occasions, their learn-by-doing training includes some tasks benefiting the locomotive restoration. That's what Leo and his team set about over the next few weeks.

This third step, after using thick oil and polishing the bearing, produced the desired effect: the axle boxes became less overheated. The final solution was actually based on a different diagnosis from the two previous steps. Using a thick oil and polishing the bearing were based on a diagnosis that focused essentially on the question of friction or rubbing. On the other hand, insulating the ash pan was based on a diagnosis that pointed to the thermal bridge created between the firebox and axles. This does not mean that the only cause of the axles overheating was that identified by the final diagnosis. In fact, it is likely that the two effectsfriction and thermal bridge-had combined to result in the hot box.

\section{Trial and Error Maintenance}

These repairs were conducted in several stages. As Ray commented on 14 March 2015: "Much has to be tested before you find a solution. And, 
after you found it, you realize it is blindingly obvious." The first diagnosis led to the bearing being adjusted and a thicker oil to be used. As these measures failed to do the trick, the ash pan was insulated. It is interesting to note that actors were neither conducting conventional repairs, nor routine maintenance. In fact, the locomotive was modified when the ash pan was insulated. For several decades, it worked without this ash pan producing the heat that caused the axle box to overheat. In contrast with the railcar derailment, no accident or breakdown caused any changes that could have explained why it would become necessary to insulate the ash pan.

I only came to understand the reason for this step after asking members of the association. A few months before, the locomotive had been fully restored, which included an entirely new firebox.

Nowadays, replacing old steam locomotive parts does not rely upon the production and distribution networks originally developed by national railways. Deprived from these resources, keepers of decommissioned rolling stock collect and store components or learn how to create them on their own. However, maintaining a steam locomotive involves activities a bit more complex than replacing a blown fuse, building your own chicken coop, or even constructing your own chain guard by welding filler steel. A tube-boiler or a firebox requires industry-specific materials, tools, and techniques. Even highly skilled volunteers are not able to construct it on their own. For these reasons, the non-profit organization has established some industry partnerships. The firebox was renewed thanks to this kind of partnership. An industry factory constructed the new firebox following the current standards, using thicker and more resistant materials than those used seventy years ago.

The sides of the new firebox are thicker than the original model. With more heat-resistant sides, the locomotive firebox requires a hotter fire to provide the same temperature to the boiler, leading to unexpected consequences regarding the overheating of the rear axle boxes. In short, when the firebox became obsolete, the restoration of the locomotive became necessary, which subsequently led to the ash pan being insulated, as part of a domino effect. This also explains why a steel blower was required, while a copper one did the job perfectly for seventy years. This also gives additional clues as to why the volunteers seem unconcerned about the presence of an original petticoat pipe in the smoke box. They are likely to modify the original design because the 
renovation of the firebox was unavoidable, as are the consequences of this replacement. For the locomotive to be able to draw a train, there is no alternative other than adapting the smoke box organs.

\section{Unavoidable Reconfigurations}

The vignette illustrates that the insulation of the ash pan and the replacement of the blower were made necessary due to a previous renovation. It shows that a repair hardly leaves things unchanged.

Such a domino effect may be overwhelming. But people involved in preserving steam locomotives know this is an endless job. Throughout all seasons, rust will have to be removed, other components will have to be replaced and substitutes will cause new issues. However, far from discouraging the rail enthusiasts, these never-ending issues stimulate them; each season brings new challenges, representing opportunities to better understand how steam engines work.

The last two vignettes show that repairs are not restricted to restoration but can introduce novelty. The firebox replacement modifies-although not purposely-how the frame conducts heat. As a consequence, volunteers envisage adding Inox cables, fitting a new blower and insulating the ash pan. These modifications were probably all required for the same reasons: the temperature inside the locomotive is possibly higher than before, due to the new firebox. Interestingly, the work conducted on the blower and on the ash pan represent improvements to the original design or, at the very least, improvements to the condition of the locomotive when it was acquired by the people that currently use it. In both cases, repairs embody a reconfiguration.

\section{Conclusion}

The repair and the maintenance of vintage engines involve multiple strategies-restoring to a previous state, replacing a broken or worn device, and adapting the original design. These strategies not only contribute to a typology of repair activities. They moreover exhibit how repairs require the combination of apparently paradoxical features, 
such as preserving while using. As tinkerers, lay railwaymen keep used devices (for components and benchmarking) and are enterprising enough to create missing components on their own. This combination of conservatism and innovation fits Do-It-Yourself (DIY) independence. But unlike isolated tinkerers, lay railwaymen illustrate a deep social organization of repair and maintenance.

First, inside the shop, breaks, double interruption rituals, support circles, and lunch talks underpin the ongoing, dynamic, and mutual contacts among members and push them to endlessly reconsider and improve the ways repairs are conducted. This informal organization helps the team to be both productive and socially cohesive. Moreover, the shop can count on five external networks within other heritage railways, some people inside national railway companies, the two instructors at the Work Training Center, partners in the industrial sector, and the large numbers of railfans taking part in their activities. As noted by Matthew Crawford (2009: 27), this demonstrates support and contributes to the motivation of the people involved in preserving old engines.

This internal and external social networking helps to collectively maintain and repair heavy rolling stocks, as volunteers have been doing for half a century. They consequently foreshadow what Web 2.0 enthusiasts have been celebrating as an innovation of the twenty-first century-amateurs with meager professional background in the field joining their efforts in order to collectively perform complex tasks. As such, like hackers, lay railwaymen foreshadow Do-It-Together or Do-It-Ourselves (Frauenfelder 2011: 51) initiatives such as Repair Cafés, Fixit Clinics (Rosner 2014), FabLabs, and the Makers movement (Lallement 2015). I therefore hope my analysis might stimulate additional fieldwork on collective repair and comparisons of the underlying dynamics and peculiarities of such initiatives.

Finally, this ethnography on collective repair of steam locomotives is an invitation to reflect on our role in modern society. First, it testifies that people originating from varied milieus can genuinely cooperate. Second, locomotive restoration workers teach us something about the human ability to interact with artifacts (Dant 2005: 135). In a world dominated by programmed obsolescence, shall we throw away a defective device or are we going to repair or maintain it? Do we really care about objects? As such, this ethnography talks about our everyday life. On a broader perspective, studying repair also matters "just because 
modern society is now in urgent need of repair" (Sennett 2012: 199). Are we going to work at restoring the world as it was before the 2008 financial crisis (Lejeune 2011b) or are we going to reconfigure it?

Acknowledgements This chapter would not exist without Nicolas Dodier's inspiring sociology of machines. I am also indebted to Patrick Italiano who initially drew my attention to this field. I want to warmly thank all the volunteers at the Three Valleys Steam Railway that welcomed me, spent time to introduce me to their activities, and treated me as a peer. A special thank you to Serge Poncé for permission to reproduce the photographs he shot (Figs. 8.4 and 8.5). I am also grateful to Manon Bertha, Rachel Brahy, Tim Dant, Thomas Vangeebergen, an anonymous reviewer, and the editors of the volume for their comments on a previous version of this chapter. David Ward, Patrick Reichert and Charles Lee helped me with the English text. Of course, I take full responsibility for the mistakes or inaccuracies that remain within this chapter.

\section{Notes}

1. Frederick Gamst (1980: 59-60) reports how professional railwaymen deal with safety rules. Johan Sanne (2014) depicts how exceptions to safety rules are negotiated between the dispatcher and railway technicians maintaining the tracks.

2. As in car garages, manuals are rarely consulted, and only for standard figures

3. Frederick Gamst (1980: 88-90) provides an alternate ethnographic account of the hot box issue.

\section{References}

Crawford, Matthew B. 2009. Shop Class as Soulcraft: An Inquiry into the Value of Work. New York: Penguin.

Dant, Tim. 2005. Materiality and Society. Maidenhead: Open University. 2010. The work of repair: Gesture, emotion, and sensual knowledge. Sociological Research Online 15 (3): 1-7.

Dodier, Nicolas. 1993. Les arènes des habiletés techniques. Raisons Pratiques 4: 115-139. 
Frauenfelder, Mark. 2011. Made by Hand: My Adventures in the World of Do-ItYourself. New York: Penguin.

Gamst, Frederick C. 1980. The Hoghead: An Industrial Ethnology of the Locomotive Engineer. New York: Holt, Rineheart and Winston.

Goffman, Erving. 1956. The Presentation of Self in Everyday Life. Edinburgh: University of Edinburgh Press.

Harper, Douglas. 1987. Working Knowledge: Skill and Community in a Small Shop. Berkeley and Los Angeles: University of California Press.

Lallement, Michel. 2015. L'âge du faire. Hacking, travail, anarchie. Paris: Seuil.

Lejeune, Christophe. 2011a. From virtual communities to project-driven mediated collectives. A comparison of Debian, Wikipedia and the Open Directory Project. In Collaborative Search and Communities of Interest: Trends in Knowledge Sharing and Assessment, ed. Pascal Francq, 10-20. Hershey: IGI Global.

- 2011b. From normal business to financial crisis... and back again: An illustration of the benefits of Cassandre for qualitative analysis. Forum Qualitative Sozialforschung/ Forum: Qualitative Social Research 12 (1) (Art. 24): 19.

Lévi-Strauss, Claude. 1962. La pensée sauvage. Paris: Plon.

Linhart, Robert. 1981. The Assembly Line. Amherst: University of Massachusetts Press.

Orr, Julian. 1996. Talking About Machines: An Ethnography of a Modern Job. Ithaca and London: Cornell University Press.

Pirsig, Robert Maynard. 1999. Zen and Art of Motorcycle Maintenance: An Inquiry into Values. New York: HarperCollins.

Rosner, Daniela K. 2014. Making citizens, reassembling devices: On gender and the development of contemporary public sites of repair in Northern California. Public Culture 26 (1): 51-77.

Roux, Baptiste. 2008. La poésie du rail. Petite apologie du voyage en train. Paris: Transboréal.

Roy, Donald. 1952. Quota restriction and goldbricking in a machine shop. American Journal of Sociology 57 (5): 427-442.

Sanne, Johan M. 2014. Vulnerable practices: Organizing through bricolage in railroad maintenance. In Vulnerability in Technological Cultures, ed. Anique Hommels, Jessica Mesman, and Wiebe E. Bijker, 199-215. Cambridge and London: MIT Press.

Sennett, Richard. 2012. Together: The Rituals, Pleasures and Politics of Cooperation. New York: Penguin.

Thibault, Martin. 2013. Ouvriers malgré tout. Enquête sur les ateliers de maintenance des trains de la Régie autonome des transports parisiens. Paris: Raisons d'agir. 